\title{
TECNÉ: DO PROJETO PROMETEICO À MODERNIDADE FÁUSTICA
}

\author{
José Rogerio Vitkowski ${ }^{1}$
}

\begin{abstract}
Resumo
Este texto resulta de uma pesquisa bibliográfica em perspectiva histórico-filosófica, e nele se aborda o problema da técnica e suas múltiplas interfaces. A abordagem cartográfica procura evidenciar conceitos e focar textos que permitem superar efeitos demasiado familiares, de senso comum, no tratamento das relações entre técnica, ciência e tecnologia. O percurso do trabalho tece visita às tradições clássicas de Homero e Hesíodo, seguida pela referência ao pensamento grego, que adensa uma interessante perspectiva sobre a técnica, compreendida como techné, expressão da produção poética — distinta da prática, "práxis", e da ciência, "episteme". Seguem registros que abrangem a conjugação entre ciência e técnica, culminando com o cenário da Modernidade Fáustica. Trata-se, portanto, de um recorte de amplo espectro que considera a técnica como forma de atividade humana, como objetos ou sistemas de objetos ou, ainda, como forma de conhecimento. Abrange, portanto, o fazer humano, homo faber; o saber, homo sapiens; o poder, homo politicus; o saber e a demência, homo sapiens-demens. Daqui resulta a compreensão de que a pesquisa do tema implica em estabelecer conexões que transversalizem múltiplos registros e discursos filosóficos, históricos, axiológicos, políticos.
\end{abstract}

Palavras-Chave: Filosofia da técnica, filosofia da tecnologia, história da tecnologia.

\section{TECNÉ: FROM THE PROMETHEAN PROJECT TO FAUSTIC MODERNITY}

\begin{abstract}
This paper results from a bibliographic research, in philosophical perspective, and it approaches the problem of technique and its multiple interfaces. The cartographic approach seeks to highlight concepts and focus texts that allow overcoming effects that are too familiar, of common sense, in treating the relations between technique, science and technology. The course of the work makes a visit to the classical traditions of Homer and Hesiod, followed by a reference to Greek thought that thickens an interesting perspective on technique, understood as techné, an expression of poetic production - distinct from practice, "praxis" and science, "episteme". Following are records that cover the combination of science and technology, culminating in the scenario of Faustic Modernity. It is, therefore, a broad spectrum cut, which considers technique as a form of human activity, as objects or systems of objects or as a form of knowledge. It therefore encompasses human doing, homo faber; knowledge, homo sapiens; power, homo politicus; knowledge and dementia, homo sapiens-demens. Hence the understanding that research on the topic implies establishing connections that cross multiple cultural, epistemic, axiological and political records and discourses.
\end{abstract}

Keywords: Philosophy of technique, philosophy of technology, history of technology.

Desde tempos imemoriais, o homem, ser extremamente frágil, estabelece relações com a natureza no desafio de sobreviver. A história dessa intervenção se dá de forma rica e complexa em um longo processo, no qual emerge e se impõe a questão técnica enquanto realidade proteiforme, dinâmica e de múltiplos entrelaçamentos, de natureza diversa, cuja

1 Doutor em Educação pela Universidade Federal de Santa Catarina (UFSC). Professor na área de Filosofia, Filosofia da Educação, Fundamentos da Educação na Universidade Estadual de Ponta Grossa (UEPG). E-mail: jrvitkowski@gmail.com. http://orcid.org/0000-0002-4821-9576 
compreensão e avaliação demandaram e demandam a atenção de incontáveis filósofos, cientistas e artistas. Pretende-se aqui percorrer alguns elementos situados nas dobras e (des)dobras desse processo, no qual será focado, ainda que en passant, o desenvolvimento e a imbricação das noções de técnica, ciência e tecnologia.

O percurso imediato deste texto terá seu início com a referência a uma classificação sobre a técnica proposta por Ortega y Gasset (1991), seguido de uma abordagem mais intensa de textos referentes às tradições míticas de Homero e Hesíodo; ato contínuo, visitaremos o pensamento grego, que adensa historicamente uma interessante perspectiva sobre a técnica, denominada techné ( $\tau \varepsilon \chi \vee \eta)$ e expressão da produção poética $(\pi \circ \imath \eta \sigma \zeta)$, distinta da prática "práxis" $\left(\pi \rho \alpha \xi_{i} \zeta\right)$ - e da ciência — “episteme” ( $\left.\varepsilon \pi 1 \sigma \tau \varepsilon \mu \eta\right)$. Das derivações do pensamento grego, seguem contornos do processo histórico conhecido como revolução científica e do casamento entre ciência e técnica no contexto da modernidade, com destaque para a Modernidade Fáustica.

Para a realização dessa tarefa, nos inspiramos nos trabalhos de Miranda (2002) e Alencastro (2003) e dialogamos com autores que aportam elementos de uma filosofia da tecnologia ${ }^{2}$, dentre eles, Cupani (2011) e Micham (1989), com destaque para dois pensadores brasileiros da Universidade de São Paulo (USP): Milton Vargas (1994; 2003) e Ruy Gama (1986). Esses últimos, engenheiros de formação, desenvolveram estudos que fornecem interessantes informações sobre a história da técnica. Destacamos ainda as contribuições dos pesquisadores Shozo Motoyama (2012), Dal Bosco (2003), Chauí (2004), Reale e Antiseri (1990), Berman (2007), Bernal (1969), Compagnon (1999) e Latour (2001).

\section{Desafiando Zeus}

À guisa de introdução, é importante frisar que, no cotidiano, os termos "técnica" e "tecnologia" se confundem, tanto pelo uso comum como pelo emprego realizado por distintos pensadores. De fato, não somente as noções de técnica e de tecnologia se confundem, se misturam, se imbricam: também a de ciência. Daí a necessidade de percorrer um caminho de

2 No âmbito acadêmico, a Filosofia da Tecnologia começa a aparecer nos congressos internacionais de Filosofia a partir da década de 1950, inicialmente na forma de debates sobre aspectos éticos e políticos das mudanças tecnológicas. Em 1965, foi realizado em São Francisco (EUA) um primeiro simpósio (“Toward a Philosophy of Tecnhology") dentro de um encontro da Sociedade de História da Tecnologia, no qual foram abordadas questões epistemológicas. Esse simpósio é apontado como o evento em que assuntos relevantes para a existência da nova disciplina foram abordados pela primeira vez. Todavia, o destaque maior para a pesquisa da nova área filosófica é atribuído ao filósofo norte-americano Paul T. Durbin (Universidade de Delaware), que organizou importantes reuniões internacionais de Filosofia da Tecnologia na década de 1970, seguido da colaboração do filósofo alemão Friedrich Rapp (CUPANI, 2011, p. 29).

\begin{tabular}{|c|c|c|c|c|}
\hline Q & Ano 10 & n. 23 & Maio - Agosto 2021 & p. $156-177$ \\
\hline
\end{tabular}


clarificação terminológica que permita acompanhar também a heterogênese, ainda que parcial e aproximada, dos respectivos conceitos.

Voltemo-nos então para a técnica e suas “origens”. De acordo com Vargas (1994, p. 18), a técnica, no sentido geral, é "tão antiga quanto o homem, pois aparece com a fabricação de instrumentos. E, de acordo com a antropologia, não há homem sem instrumentos, por mais rudimentares que sejam". Assim, a fabricação da pedra lascada e o aparecimento do homem seriam simultâneos, e a essa fabricação já corresponderia um saber fazer, embora a techné propriamente dita só tenha aparecido na Grécia Clássica.

As técnicas das comunidades primitivas permitiam que os humanos criassem ferramentas e instrumentos que os protegessem, mas também que aumentassem a extensão do seu corpo, reduzindo, assim, as dificuldades do trabalho braçal. São conhecidos os exemplos do martelo, que aumenta a potência do braço, e do arado, que, como uma mão, permite cavar na terra. Desse modo, ao mesmo tempo em que se adaptava à natureza, o homem nela interferia e a "moldava" através das técnicas que desenvolvia.

O filósofo José Ortega y Gasset (1833-1955) escreveu um conjunto expressivo de textos sobre a técnica, designado Meditação sobre a Técnica, no qual esboça uma periodização muito útil. $\mathrm{O}$ autor distingue três grandes períodos da técnica, denominando-as de "fases", e usou o termo "evolução" das técnicas, a saber: a) a técnica do acaso; b) a técnica do artesanato; c) a técnica do técnico. ${ }^{3}$ Aprofundemos inicialmente o primeiro item.

O nome "técnica do acaso" deriva de que o acaso é aí o técnico, é o que proporciona o invento. Trata-se da técnica primitiva. O homem primitivo ignora sua própria técnica enquanto tal, ou seja, não se dá conta de que, entre suas capacidades, existe uma que lhe permite reformar a natureza na direção que lhe aprouver. O conjunto dos atos técnicos não tem um corpo definido, diferenciado do repertório de atos naturais. Também a simplicidade e a escassez da técnica primitiva trazem consigo o fato de que os atos são exercidos por toda uma coletividade, com algumas diferenças de gênero. Acrescente-se ainda que o caráter inventivo ou da invenção não é prioritário. As soluções de problemas se dão num ambiente no qual a dimensão mítica, da magia, é preponderante. Assim, as técnicas primitivas têm originalmente

3 Ao abordar as fases da técnica, Ortega y Gasset (1991) alerta para o inconveniente ou erro de tentar classificar as fases por meio apenas do aparecimento de um invento específico. Assim, opta por outro caminho, pensando a função técnica em geral como princípio esclarecedor. Ao assumir essa posição, o autor argumenta que há técnicas magníficas que se perderam ou desapareceram definitivamente ou que tiveram de ser redescobertas. Além disso, não basta que se invente algo num determinado momento e lugar para que o invento venha a representar ou exaurir seu próprio significado. Exemplos notórios são a pólvora e a imprensa, descobertas que já existiam há séculos, mas somente na modernidade recente assumiram significados históricos de grande vulto.

\begin{tabular}{|c|c|c|c|c|}
\hline Revista कi & Ano 10 & n. 23 & Maio - Agosto 2021 & p. $156-177$ \\
\hline
\end{tabular}


uma dimensão mágica e só são técnicas pelo que têm de magia. Para Ortega y Gasset (1991, p. 58), esse homem "não se reconhece, pois, a si mesmo como inventor de seus inventos. A invenção lhe aparece mais como uma dimensão da natureza - o poder que esta tem de lhe proporcionar, ela a ele e não o contrário, certos poderes".

É conhecido que as técnicas mais primitivas de que se tem notícia, como o uso do fogo e o polimento de pedras, estão situadas no período Paleolítico (3,5 milhões a 10 mil anos a.C.). Já no período seguinte, o Neolítico (8 mil a 5 mil anos a.C.), há um grande desenvolvimento da técnica com as atividades da agricultura, o pastoreio de animais e a cerâmica. Na continuidade histórica, temos a descoberta dos metais, como o ferro e o bronze; essas novas conquistas promovem outras transformações no mundo e nas sociedades. É bom frisar que essas técnicas, em conformidade com o pensamento mítico-mágico-religioso, eram tidas como presentes dos deuses; os saberes eram considerados secretos e transmitidos a um número seletíssimo de pessoas.

A técnica é, portanto, tão antiga quanto o homem. Seu surgimento é marcado pela dimensão mágica e simbólica. Vargas (1994, p. 19) explica a peculiaridade mágica das técnicas:

Todas as técnicas tiveram origem mágica. Desde o arado que penetrava a mãe terra para fecundá-la e que, portanto, tinha a forma de um falo, até a medicina grega originária do deus Asclépio - que curava os doentes durante o seu sono - passando pela forjaria e a tempera dos aços das espadas árabes em que os cavaleiros arrebatavam as espadas das forjas, e as temperavam e brandiam-nas contra o vento combatendo espíritos. [...] A transmissão dos conhecimentos técnicos de geração a geração foi também inicialmente feita como segredos revelados pelos deuses e, portanto, a uma corporação. De uma forma positiva, entretanto, pode-se pensar a invenção das técnicas e a sua transmissão de geração a geração como baseado num instinto esclarecedor.

A relação da técnica com o universo mágico está presente em muitas narrativas, singularmente nas míticas gregas, como no mito de Prometeu. Esse mito, de diferentes versões, está presente nas grandes narrativas clássicas do Protágoras, de Platão; Prometeu, de Ésquilo; e Teogonia e Erga ${ }^{4}$, de Hesíodo. Apresentamos, a seguir, alguns trechos dessa interessante narrativa. Em Os trabalhos e os dias, de Hesíodo, (1996, p. 25) encontramos:

\footnotetext{
Oculto retém os deuses o vital para os homens; Senão comodamente em um só dia trabalharias Para teres por um ano, podendo em ócio ficar; Acima da fumaça logo o leme alojarias, Trabalhos de bois e incansáveis mulas se perderiam. Mas Zeus encolerizado em suas entranhas ocultou, pois foi logrado por Prometeu de curvo-tramar;
}

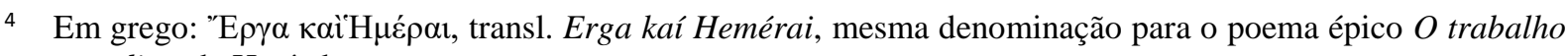
e os dias, de Hesíodo.

\begin{tabular}{|c|c|c|c|c|}
\hline Rovista Dialectus & Ano 10 & n. 23 & Maio - Agosto 2021 & p. $156-177$ \\
\hline
\end{tabular}


por isso para os homens tramou tristes pesares: ocultou o fogo. E de novo o bravo filho de Jápeto roubou-o do tramante Zeus para os homens mortais em oca férula, dissimulando-o de Zeus frui-raios.

Então encolerizado disse o agrega-nuvens Zeus: "Filho de Jápeto, sobre todos hábil em tuas tramas, Apraz-te furtar o fogo fraudando-me as entranhas, Grande praga para ti e para os homens vindouros! Para esses em lugar do fogo eu darei um mal e todos se alegrarão no ânimo, mimando muito esse mal".

Assim, o titã Prometeu roubou dos deuses o segredo do fogo e o revelou aos homens. Zeus castigou-o. Na sequência do texto supracitado, Pandora será enviada como castigo que espalhará toda a espécie de sofrimento aos humanos. Já em outra narrativa do mesmo mito, temos no Protágoras, de Platão, uma interessante descrição sobre a origem das técnicas. Ainda que longos, seguem alguns recortes que descrevem importantes aspectos do mito:

\begin{abstract}
Houve um tempo em que só havia deuses, sem que ainda existissem criaturas mortais. Quando chegou o momento determinado pelo Destino, para que estas fossem criadas, os deuses as plasmaram nas entranhas da terra [...] Ao chegar o tempo certo de tirálos para a luz, incumbiram Prometeu e Epimeteu ${ }^{5}$ de provê-los do necessário e de conferir-lhes as qualidades adequadas a cada um. Epimeteu, porém, pediu a Prometeu que deixasse a seu cargo a distribuição. Depois de concluída, disse ele, farás a revisão final [...] Nessa tarefa, a alguns ele atribuiu força sem velocidade, dotando de velocidade os mais fracos; a outros deu armas; para os que deixara com a natureza desarmada, imaginou diferentes meios de preservação [...]. Como, porém, Epimeteu carecia de reflexão, despendeu, sem o perceber, todas as qualidades que dispunha, e tendo ficado sem ser beneficiada a geração dos homens, viu-se por fim, sem saber o que fazer com ela. Encontrando-se nessa perplexidade, chegou Prometeu para inspecionar a divisão e verificou que os animais se achavam regularmente providos de tudo; somente o homem se encontrava nu, sem calcados, sem coberturas, nem armas [...]. Não sabendo Prometeu que meio excogitasse para assegurar ao homem a salvação, roubou de Hefesto e de Atena a sabedoria das artes junto com o fogo - pois sem o fogo, além de inúteis as artes, seria impossível o seu aprendizado - e os deu ao homem. Assim, foi dotado o homem com o conhecimento necessário para a vida; mas ficou sem possuir a sabedoria política; esta se encontrava com Zeus, e a Prometeu não era permitido penetrar na acrópole, a morada de Zeus. Assim a ocultas penetrou no compartimento comum em que Atena e Hefesto amavam exercitar suas artes, e roubou de Hefesto a arte de trabalhar com o fogo, e de Atena a que lhe é própria, e as deu aos homens. Desse modo, alcançou o homem condições favoráveis para viver. Quanto a Prometeu, consta que foi posteriormente castigado por esse furto, levado a cabo por culpa de Epimeteu (PLATÃO, 2002, p. 65s).
\end{abstract}

Ainda em outras versões do mesmo mito, particularmente em Prometeu Acorrentado, de Ésquilo (2005, n.p.), aparece uma descrição pormenorizada dos favores divinos mediatos pela ação prometeica.

5 O nome "Epimeteu" significa "aquele que compreende os fatos depois de terem eles acontecido", ao contrário de seu irmão, Prometeu, cujo nome indica que tem deles uma espécie de pré-ciência.

\begin{tabular}{|c|c|c|c|c|}
\hline Q & Ano 10 & n. 23 & Maio - Agosto 2021 & p. 156-177 \\
\hline
\end{tabular}


Ouvi, somente, quais eram os males humanos, e como, de estúpidos que eram, eu os tornei inventivos e engenhosos. Eu vo-lo direi, não para me queixar deles, mas para vos expor todos os meus benefícios. Antes de mim, eles viam, mas viam mal; e ouviam, mas não compreendiam. Tais como os fantasmas que vemos em sonhos, viviam eles, séculos a fio, confundindo tudo. Não sabendo utilizar tijolos, nem madeira, habitavam como as providas formigas, cavernas escuras cavadas na terra. Não distinguiam a estação invernosa da época das flores, das frutas, e da ceifa. Sem raciocinar, agiam ao acaso, até o momento em que eu lhes chamei a atenção para o nascimento e ocaso dos astros. Inventei para eles a mais bela ciência, a dos números; formei o sistema do alfabeto, e fixei a memória, a mãe das ciências, a alma da vida. Fui eu o primeiro que prendi os animais sob o jugo, a fim de que, submissos à vontade dos homens, lhes servissem nos trabalhos pesados. Por mim foram os cavalos habituados ao freio, e moveram os carros para as pompas do luxo opulento. Ninguém mais, senão eu, inventou esses navios que singram os mares, veículos alados dos marinheiros. Pobre de mim! Depois de tantas invenções, em benefício dos mortais, não posso descobrir um só meio para pôr fim aos males que me torturam.

E é nessa narrativa, de Ésquilo, que se encontra o conhecido e duro castigo daquele que ousou premiar os humanos. Prometeu está relutante em aceitar as penas divinas, mas seu interlocutor é impiedoso e manifesta que uma águia devorará continuamente seu fígado:

Visto que não logrei persuadir-te, pensa, ao menos, na tempestade de novas desgraças
que hão de cair sobre ti. Júpiter, por meio de raios, espedaçará este rochedo escarpado;
teu corpo permanecerá esmagado sob os fragmentos da montanha. Ao cabo de longo
tempo, reaparecerás um dia... Então, um abutre insaciável, — o cão alado de Júpiter
— virá arrancar de teu corpo enormes pedaços e, - comensal não desejado - voltará
todos os dias para se nutrir de teu fígado negro e sangrento. Desse tremendo suplício
não esperes ver o fim, salvo se algum deus quiser ficar em teu lugar [...] o que digo
não é uma série de vãs ameaças; é uma sentença inapelável (ESQUILO, 2005, S/p.).

Entre as interpretações dessas instigantes e belas narrativas mitológicas está a de Vernant apud Motoyama (1995). De acordo com o autor, o mito de Prometeu é uma representação simbólica do surgimento do trabalho e da técnica.

$\mathrm{O}$ mito remete aos tempos ancestrais, quando os homens rompem com a dependência divina para assumirem a responsabilidade de produzir a sua sobrevivência por meio do trabalho e com o auxílio dos artifícios e objetos técnicos. Contudo, isso não foi bem visto pelo olhar dos deuses do Olimpo, e essa ação será interpretada negativamente como fraude ou, literalmente, como roubo. E como os deuses não permaneceram indiferentes, ocorre a punição devido à ousadia humana. Desde então, os simples mortais deverão contar com sua própria habilidade e arte para sobreviver. Os infortúnios, as dores e sofrimentos serão o castigo divino para a ousadia diante dos deuses. Assim, a aventura humana iniciada com o trabalho e o desenvolvimento da técnica estará sempre sob vigilância severa dos deuses. Não obstante, a audácia prometeica dos humanos parece nunca ter fim e estará ancorada no desenvolvimento e nas mutações da própria técnica, isto é, da ciência e da tecnologia. A tecnologia apresenta, portanto, uma interessante dimensão transgressora. Assim, nesse rico e longo processo de

\begin{tabular}{|l|l|l|l|l|}
\hline Q & Ano 10 & n. 23 & Maio - Agosto 2021 & p. $156-177$ \\
\hline
\end{tabular}


humanização, o ser humano aperfeiçoa o seu próprio fazer: surge um saber-fazer, uma técnica, expressão do homo faber, face indissociável do homo sapiens-demens.

\section{A techné na terra de Homero}

Com o gradativo distanciamento do pensamento mítico, emergirá um novo modo de pensar, um novo modo de produzir conhecimento: a filosofia. É nessa paisagem que se insere uma nova noção de técnica, a saber, a noção grega de techné. É no mundo grego que as técnicas se transformam de saberes sagrados e mágicos, de índole mítica, em que os deuses detinham o monopólio do saber e do fazer instrumentos e utensílios, para uma atividade outra, a techné, um saber-fazer aperfeiçoado pelo homem e passível de ser transmitido de geração em geração.

De acordo com Vargas (1994), a techné grega e seu prolongamento, a ars romana, são uma forma elaborada e sistematizada de técnica. Uma técnica aperfeiçoada pela educação, de geração a geração, chegando mesmo a ser apresentada e descrita em livros e compêndios e não simplesmente sabida quase em segredo - como era a magia — pelos profissionais.

Ortega y Gasset (1991) denomina esse segundo estágio da técnica de "técnica do artesanato" ou "técnica do artesão", o qual abrange a Grécia e a Roma antigas e a Idade Média. Enquanto técnica mais desenvolvida, esse período traz como grande característica o aperfeiçoamento técnico, a unidade fazer-saber, e especialmente seu caráter educativo por meio da aprendizagem associativa. O filósofo espanhol indica várias peculiaridades dessa fase ${ }^{6}$.

Seguindo nosso objetivo, voltamo-nos novamente para o pensamento grego, ressituando a noção de techné no contexto grego. Uma breve incursão no registro aristotélico de ciência é pertinente para dar maior envergadura à questão. De acordo com Chauí (2004), são três grupos da ciência aristotélica, a saber: ciências produtivas, ciências práticas e ciências teóricas.

6 Considerando que a proporção entre o técnico e o não técnico ainda não é absoluta, a primeira grande característica da "técnica do artesanato" é o crescimento dos atos técnicos, a ponto de nem todas as pessoas poderem exercê-los. Assim surgirão os artesãos como homens singulares que dominam as técnicas e as exercem unitariamente: fazer e saber fazer. No artesanato, ainda não aparece a consciência do invento. Caberá ao artesão aprender, através de extensa aprendizagem, técnicas que já estão elaboradas e que estão postas na tradição, daí a época dos mestres e aprendizes e também o caráter formal de tradição que se dá no seguimento desse ou daquele mestre. O artesão é inspirado pelo princípio de encaixar-se numa tradição e está voltado para o passado. Apesar dos aperfeiçoamentos que surgem gradativamente, eles se dão como variações de estilo nas habilidades que são transmitidas na forma de escolas. Outra característica é que, até aqui, existe invenção de instrumentos, mas não de máquinas. No artesanato, o utensílio ou ferramenta é complementar ao homem, que continua no primeiro plano. No caso da máquina, ao contrário, o instrumento passa para o primeiro plano (ORTEGA Y GASSET, 1991, p. 61-65).

\begin{tabular}{|c|c|c|c|c|}
\hline Q & Ano 10 & n. 23 & Maio - Agosto 2021 & p. $156-177$ \\
\hline
\end{tabular}


As ciências práticas são designadas pelo termo "práxis", significando o estudo das práticas humanas enquanto ações que têm nelas mesmas seu próprio fim, isto é, a finalidade da ação é ela mesma. Não há distinção entre o agente e o ato que se realiza. Exemplos dessas ciências são a Ética e a Política.

As ciências produtivas são designadas pelo termo grego poiésis, significando produção, manufatura. São objeto das ciências produtivas todas as atividades humanas, técnicas e artísticas, que resultam em um produto ou obra distintos do produtor. Exemplos dessas ciências são a Arquitetura (cujo fim é a edificação de uma coisa), a Economia (cujo fim é a produção agrícola, o artesanato e o comércio), a Medicina (cujo fim é produzir a saúde e a cura), a pintura, a escultura, a poesia, o teatro, dentre outras.

As ciências teoréticas ou contemplativas são designadas pelo termo teoresis e estudam aquilo que existe independentemente dos homens e suas ações, mas que só pode ser contemplado pelos homens: as coisas da natureza e as coisas divinas. Recorde-se que o termo teoria significa, em grego, "contemplação da verdade". Estão nesse grupo de ciências a Física, a Matemática, a Astronomia e a ciência mais importante, denominada de "ciência primeira", que será chamada mais tarde de Metafísica: "ciência do ser enquanto ser".

Essas distinções no registro aristotélico podem agora ser inter-relacionadas. Simplificadamente temos: da poiésis deriva um tipo de ação relacionada ao fazer ou produzir; da práxis, por sua vez, uma ação denominada de agir; e da episteme, um contemplar. Essas indicações iniciais precisam agora ser aprofundadas.

A techné pertence à classificação das ciências produtivas. De fato, os artesãos ou técnicos gregos detinham um saber tácito - diríamos hoje uma espécie de know-how - para bem realizar coisas e obter resultados. Assim, a techné era uma atividade para resolver problemas práticos da sobrevivência humana, distinta da noção de práxis e da episteme. De acordo com Vargas (1994, p. 18):

\footnotetext{
As "techné" gregas eram, em princípio, constituídas por conjuntos de conhecimentos e habilidades profissionais transmissíveis de geração a geração. São desse tipo de saber a medicina e a arquitetura gregas. Também são "techné" a mecânica, entendida essa como a técnica de fabricar e operar máquina de uso pacífico ou guerreiro, e os ofícios que hoje chamamos de "belas artes". Ao lado dessas havia também uma "techné" exata como, por exemplo, a utilização das matemáticas na agrimensura e no comércio. Mas não se deve entender "techné" como um saber operativo - manual. Com efeito, o conceito de "techné" é mais extenso.
}

Um exemplo que pode elucidar a racionalidade da poiésis, na qual se insere a techné, é apontado por Milton Vargas (1994): o médico grego Hipócrates. Uma das obras desse

\begin{tabular}{|l|l|l|l|l|}
\hline Q Rovista Dialectus & Ano 10 & n. 23 & Maio - Agosto 2021 & p. 156-177 \\
\hline
\end{tabular}


médico chamava-se precisamente Techné e tinha como finalidade transmitir aos aprendizes como praticar bem e eficazmente a medicina. Esse tratado tem como premissa a necessidade imprescindível de que, na medicina, não se deve tomar como objeto a preocupação em explicar a doença, mas sim curar o doente. Isso indica que a característica da techné é de ser um conhecimento prático e aplicado. A medicina, assim vista, tinha como objeto curar as doenças e por isso se valia de preceitos e receitas fundados na prática dos médicos já experientes e repassados aos aprendizes. Hipócrates dizia que a medicina filosófica, baseada na filosofia da natureza, era inútil, sem interesse para o doente, fugindo inclusive ao dever do médico, que é curar.

O conceito de techné é, portanto, bastante extenso ${ }^{7}$, embora esteja marcado pelo "saber prático" ou e pelo fazer algo de prático eficientemente. Sendo um "saber prático", a techné era considerada distinta dos outros saberes ou ciências, particularmente da práxis. Ao pensar a distinção entre poiésis e práxis, Dalbosco (2003, p. 43) aponta: "Embora ambos os tipos de ação sejam orientados teleologicamente, ou seja, são ações que se deixam orientar pela relação meio-fim, Aristóteles deixa claro que produzir e agir não são a mesma coisa". Para o clássico filósofo, agir e produzir não se equivalem, "por isso, a disposição acompanhada de razão, que se dirige à ação, é distinta da disposição, igualmente acompanhada de razão, que se dirige até a produção" (DALBOSCO, 2003, p. 43).

Dalbosco traz ainda um importante esclarecimento quanto à diferença entre as ciências supracitadas. Para o autor, "o objeto da poiésis é a obra, ao passo que o da práxis é a boa ação; a poéisis volta-se para a produção de uma obra que deve servir a um determinado emprego, da práxis, para a realização de uma boa ação" (DALBOSCO, 2003, p. 43). O autor acrescenta ainda outra diferença sobre as racionalidades que presidem essas ciências: "a racionalidade poiética orienta-se para uma finalidade externa, ao passo que a racionalidade da práxis encontra em si mesma a sua finalidade" (DALBOSCO, 2003, p. 44).

Perceba-se que as distinções ajudam a perceber as fronteiras na relação com a techné. Enquanto saber eminentemente prático, a techné não era, no registro grego, capaz de dar conta dos princípios últimos das coisas. É nesse contexto que a episthéme, enquanto saber teórico e contemplativo, toma vulto. Pertencendo ao grupo das ciências teoréticas e enquanto

7 No Protágoras, Platão estende o conceito para abranger a arte política — isto é, um saber dirigido aos fins práticos de governo, baseado nas virtudes cívicas para as quais não só o aprendizado como também o exercício requeria uma techné (VARGAS, 1994, p. 18). A palavra grega techné tem uma extensão maior que a latina ars e pressupõe uma conduta certa numa atividade específica, subordinada a uma série de conhecimentos adquiridos através da educação (VARGAS, 1994, p. 19).

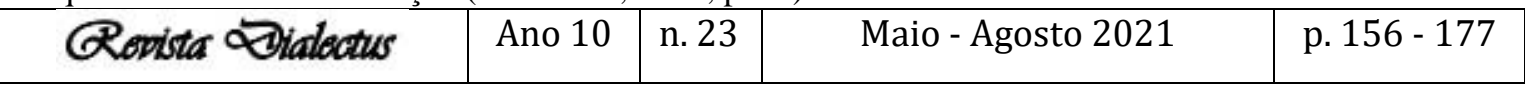


teoria, era considerada um conhecimento puro e contemplativo, que buscava a essência da natureza. Aristóteles distinguia a episthéme da techné e considerava a primeira mais completa que a segunda, pois aquela tratava das coisas universais e necessárias, ao passo que esta tratava de coisas variáveis. O que é interessante nessas distinções, para nosso intento, é que a noção de techné, embora relacionada ao fazer ou a um saber-fazer, não se reduz a uma atividade meramente operativa. Essa observação encontra-se em outros estudiosos do tema.

O historiador da filosofia Giovanni Reale (1995) esclarece que a palavra grega techné implica, ao mesmo tempo, conhecimento do universal e aplicação prática, com a predominância do primeiro sobre a segunda. Portanto, o sentido de técnica empregado pelos gregos diz respeito a um conhecimento universal aplicado à prática, como o do artesão, que, ao produzir um utensílio, tinha a dimensão da totalidade do objeto produzido. Essa distinção é significativa, pois, na modernidade, com a parcialização do trabalho, temos a predominância do aplicacionismo prático, descurando-se do "conhecimento universal". Além disso, torna-se inexata a equivalência entre techné e arte, tal como conhecemos hoje. A esse propósito, Reale (1995, p. 250) explica:

A palavra techné tem em grego uma extensão muito mais vasta que a nossa palavra arte. Com essa se pensa uma atividade profissional qualquer fundada sobre um saber especializado, isto é, não só a pintura, a escultura, a arquitetura e a música, mas também, e mais ainda, a arte sanitária, a arte da guerra e até mesmo a arte do piloto. E dado que a palavra exprime que tal consuetude ou atividade prática não se apoia só sobre uma rotina, mas sobre regras gerais e sobre conhecimentos seguros, ela chega facilmente ao significado de "teoria", significado que tem correntemente na filosofia de Platão e de Aristóteles, onde se trata de contrapô-la à pura empiria ou "prática". Por outro lado, techné se distingue de epistéme, "a ciência pura, enquanto a techné é pensada sempre a serviço de uma práxis".

Nota-se, portanto, que a noção de techné, mesmo sendo distinta, conserva parentesco com as noções de práxis e de episthéme. Todavia, há outra consideração que pode ser retomada e que relaciona a noção de techné com outro vigoroso conceito grego, a phronesis, do qual se ocupou Aristóteles. Tomamos como referência os trabalhos de Georges Cottiers apud Miranda (2002, p. 28):

O VI livro da Ética a Nicômaco é consagrado à prudência (phronesis) que é a virtude da decisão certa e justa. Para determinar o que esta virtude tem de específico, o filósofo a comparava às virtudes intelectuais, à ciência, à arte (techné), à sapiência, à inteligência intuitiva. A aproximação entre phronesis e techné se impõe de modo especial porque ambas pertencem à razão prática. Têm em comum que uma versa sobre "o que é que pode ser de outro modo", qual é seu contingente, por oposição ao necessário, que é objeto da ciência propriamente dita. De resto, diferem-se a poiésis, a criação, e a práxis, a ação ética. A techné se refere à primeira, phronesis à segunda. 
O que se evidencia é que, para o filósofo estagirita, a técnica está ligada à noção de prudência; mais que isso, ela é a virtude mais puramente intelectual da prudência. É a razão que dirige a produção. No esclarecimento das noções aristotélicas, acompanhamos ainda as observações de Cottier apud Miranda (2002, p. 28):

Poiésis pode em realidade ser traduzida como produção, fazer, fabricação, criação. Os Latinos dirão ars factvia. A razão certa se refere àquela verdade prática que é a verdade técnica; esta tem competência sobre a forma e a medida que o produtor dá ao objeto produzido. De resto cada arte tem por objeto fazer vir qualquer coisa à existência (gênesis) e a explicação da arte consiste em descobrir (techmazein $e$ theorein) os meios ou, (o como) fazer vir à existência uma ou outra das coisas que possam ser ou não ser e cujo princípio reside no produtor e não na coisa produzida. Porque a arte não tem por objeto nem as coisas que são ou vêm à existência necessariamente, nem as coisas que são ou vêm a existência por natureza, do momento que aquelas coisas têm seus princípios nelas mesmas.

É interessante essa perspectiva da técnica relacionada "à virtude da direção certa", como prudência. Esse significado pode ser um importante adensamento para se pensar que a noção de técnica transborda para outras dimensões do humano, notadamente, as dimensões valorativas que incidem no ethos de uma sociedade. Todavia, não é desconhecido que essa dimensão de eticidade é frequentemente obliterada. Aliás, o que se percebe é que, apesar das sutis distinções do pensamento grego ao referir-se à episthéme e à techné, prevaleceu historicamente a dicotomia entre o saber e o fazer, deixando-se de lado os finos e imbricados laços apontados na terra de Homero.

Fechando esse tópico, cumpre registrar que, com o declínio da hegemonia grega ${ }^{8} \mathrm{e}$ emergência dos romanos, há uma espécie de prolongamento da noção de técnica anteriormente referida. As artes romanas, das quais a arquitetura e a medicina se destacaram, são expressão esmerada do desenvolvimento das técnicas. A arquitetura romana, por exemplo, pode ser vista ainda hoje nos seus aquedutos, estradas, muralhas, edificações. Isso demonstra o quanto os romanos foram dedicados às técnicas e às artes. Aliás, é sob o nome latino de "artes" que o saber técnico será preservado e desenvolvido na Idade Média. A exemplo dos gregos e romanos, eram várias as artes; além da arquitetura e da medicina, havia a navegação, a caça, as artes militares e também o direito. Também havia as belas artes, como a escultura e a pintura, bem

8 Shozo Motoyama (1995) registra que durante o período Helenístico, centrado em Alexandria, houve lampejos de grandes avanços técnicos em torno do museu e da célebre biblioteca. A riqueza de trabalho científico e técnico suscitou ousadas teses. Como a de Farrington, advogando a utilização do método experimental de cunho moderno entre os pesquisadores alexandrinos. Outra tese advém de Bertrand Gille. Esse historiador da técnica defende a ideia de que a tecnologia, no sentido moderno do termo, nasceu entre os "mecânicos alexandrinos" (MOTOYAMA, 1995 p. 19-20).

\begin{tabular}{|c|c|c|c|c|}
\hline Q Rovista Dialectus & Ano 10 & n. 23 & Maio - Agosto 2021 & p. $156-177$ \\
\hline
\end{tabular}


como as artes da mineração e a forjaria. No seu conjunto, essas artes mantinham a perspectiva da techné.

\section{Novos cenários: a revolução científica}

Com o declínio da hegemonia grega (aproximadamente no século II a.C.) e o advento e declínio do Império Romano, somados a outros eventos históricos, como o cristianismo, um novo cenário se constituirá para o desenvolvimento da técnica e da ciência.

Até o final da Idade Média, temos, em largos traços, uma sociedade feudal com visão de mundo teocêntrica; o pensamento hegemônico se assentava na fundamentação platônico-agostiniana e depois na aristotélica-tomista, que consideravam de maior significância as questões referentes a Deus, à alma humana e à ética. O objetivo principal da filosofia era servir de base à teologia e tinha como causa de suas preocupações a salvação da alma após a morte. Foi um período de contemplação do universo, de respeito às autoridades constituídas, de hipervalorização dos textos bíblicos e gregos. Nesse longo período histórico, sabe-se que houve o desenvolvimento de diferentes técnicas e inventos significativos.

Todavia, no que tange à ciência medieval propriamente dita, há vários limites. Um deles é a diminuição do interesse pelos estudos da natureza nos primeiros séculos do período medievo. Somente a partir do século XIII haverá um novo despertar para a natureza. Desse modo, a ciência medieval é filha de sua época, por isso, não é correto esperar de tal ciência mais do que lhe era pedido no seu tempo. Bernal elucida essa questão:

Tanto para muçulmanos como para cristãos a ciência natural tinha apenas uma parte, e não muito importante, na grande tarefa de justificar a ordem divina do universo, cujas características principais eram dadas pela revelação e suportadas pela razão [...]. Robert Grosseteste, talvez o pensador medieval de mente mais penetrante que maior influência teve no desenvolvimento da ciência medieval, considerava a ciência essencialmente como um meio de ilustrar verdades teológicas; o seu estudo da luz e a sua verificação por meio de experiências concretas da refracção das lentes foram feitas porque concebia a luz como fenômeno análogo à iluminação divina (BERNAL, 1969, p. 331).

É em meio a essa ambiência teocêntrica que se pode entrever o pensamento técnicocientífico medieval. Outro exemplo significativo refere-se a Roger Bacon (1214-1294). Esse filósofo é considerado um dos grandes pensadores que defendiam uma ciência a serviço do homem, bem como a conquista da natureza, todavia, de acordo com Bernal (1969, p. 330):

Embora tivesse previsto navios a motor, carros e aviões, e uma ciência da alquimia que nos ensine a descobrir coisas capazes de prolongar a vida humana -, o seu interesse pela ciência era fundamentalmente teológico, para ele, o conhecimento

\begin{tabular}{|l|l|l|l|l|}
\hline Q & Ano 10 & n. 23 & Maio - Agosto 2021 & p. $156-177$ \\
\hline
\end{tabular}


científico era apenas parte, juntamente com a revelação, de uma sensatez integral a ser contemplada, experimentada e utilizada ao serviço de Deus.

Note-se que é a esse horizonte, de cunho finalista-religioso, de aspiração universal, de hierarquias definidas, de uma cosmologia de perfeição, que se dirigia o pensamento medieval e no qual se ordenava todo o conhecimento disponível na época.

Com o advento do Renascimento, essa imagem de mundo, de sociedade, de conhecimento será quebrada gradativamente. O retorno à cultura helenística, a retomada do interesse pelo conhecimento da natureza, aliados à dimensão humanista, na qual o homem será focado como centro de todas as coisas, prepararão a emergência de uma nova fase da história humana, conhecida como modernidade. Instaura-se então uma nova fase do desenvolvimento da ciência, cujos fundamentos remontam aos séculos XVI e XVII, em um período que ficou conhecido como Revolução Científica.

Sobre essa etapa da história da ciência, acontecida nos séculos XVI e XVII, Reale e Antiseri (1990, p. 185) estabelecem, na história da Filosofia, a relação dos seus principais personagens:

O período de tempo que vai mais ou menos da data de publicação do Revolutionibus, de Nicolau Copérnico, isto é, de 1543, à obra de Isaac Newton, Philosophiae naturalis principia mathematica ${ }^{9}$ que foi publicada pela primeira vez em 1687, hoje é comumente apontado como o período da "revolução científica". Trata-se de um poderoso movimento de ideias que adquire no século XVII as suas características determinantes na obra de Galileu, que encontra os seus filósofos - em aspectos diferentes - nas ideias de Bacon e Descartes e que depois iria encontrar a sua expressão agora clássica na imagem newtoniana do universo concebido como uma máquina, ou seja, como um relógio. O mundo que se transforma. Junto a essa transformação, ocorre também a mudança das ideias sobre o homem, sobre o trabalho científico e as instituições científicas, sobre as relações entre ciência e fé religiosa.

As questões levantadas pela revolução científica podem assim ser explicitadas:

a) Copérnico tira a Terra do centro do universo e, com ela, o homem.

b) Mudando a imagem do mundo, muda a imagem do homem. Mas também, progressivamente, muda a imagem da ciência.

c) Com a revolução científica abriu-se caminho para as categorias, os métodos, as instituições, os modos de pensar e os valores relacionados com aquele fenômeno que, depois da revolução científica, costumamos chamar ciência moderna. E o traço mais característico desse fenômeno que é a ciência moderna resume-se precisamente no método.

d) Juntamente com a cosmologia aristotélica, a revolução científica leva à rejeição das categorias, dos princípios e das pretensões essencialistas da filosofia aristotélica. [...] Não é mais o que, mas o como; não é mais a substância, mas sim a função que a ciência galileana e pós galileana passariam a indagar (REALE; ANTISERI, 1990, p. 185).

9 "Princípios matemáticos da filosofia natural".

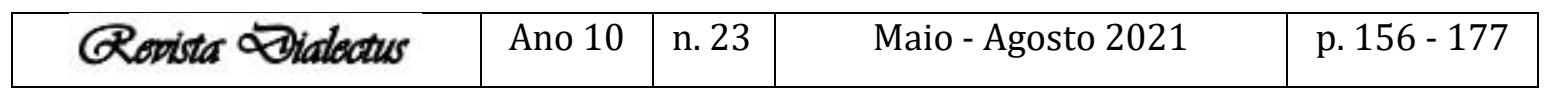


Desse modo, a revolução científica transforma o modo de produção do conhecimento, colocando o método como centro da ciência moderna. E é devido à preocupação com uma nova ciência que se busca, a partir de então, a descrição objetiva da realidade por meio da observação e da mensuração dos corpos e da experimentação dos objetos. O esforço de compreensão e domínio da natureza se dará implacavelmente, privilegiando-se, desde então, o estudo das causas mecânicas e eficientes dos objetos, postergando as noções de causa final.

\section{O casamento da técnica com a ciência}

Antes de dar continuidade à abordagem já iniciada, faremos uma rápida digressão para algumas anotações terminológicas. A palavra tecnologia, em sentido etimológico estrito, vem do grego techné $=$ arte e logos $=$ discurso, razão.

Se a técnica é tão antiga quanto a humanidade, no que tange à tecnologia pode-se afirmar diferente. O uso polissêmico do termo "tecnologia", os adensamentos, o uso por contraste, dificultam a localização de uma definição histórica precisa ou "original", como demonstra Rui Gama em seus estudos histórico-filológicos (1986). Todavia, daqui podem-se obter alguns apontamentos interessantes. Limitar-nos-emos a algumas ilustrações. ${ }^{10}$

$\mathrm{O}$ autor acima referido assinala que o termo chega até nós com mais frequência através do inglês, technology, cuja tradução é problemática devido ao grande número de significados. Ele indica ainda que a palavra francesa technologie:

[é] usada com parcimônia, embora na linguagem dos negócios e da indústria seja muito usada, talvez até pelas "consequências práticas" em termos de competição comercial. Porém o uso de technologie como versão francesa de technology encontra resistência pelo lado Francês, pois trata de histórias diferentes que se cruzam num conceito que é apenas aparentemente o mesmo (GAMA, 1986, p. 39).

Essa citação já dá o clima do exame semântico que o autor realiza na difícil tarefa de evidenciar elementos constantes ou dominantes.

Na língua portuguesa, a palavra aparece na obra do Padre Rafael Bluteau, que, no Prólogo, qualifica seu vocabulário de “Technológico", a saber, de techni = arte, porque se ocupa de todas as artes liberais e mecânicas.

10 De acordo com Ruy Gama, o Dicionário Etimológico da Língua Portuguesa, de Antenor Nascentes, dá como origem a palavra grega Technologia, e o Dictionaire Grec-Français, de A. Bailly, dá para $\tau \varepsilon \chi \nu o \lambda o \gamma ı \alpha$ significado de "tratado ou dissertação de uma arte". O importante é que Bailly assinala sua presença na obra de Cícero (106 a.C - 43 a.C.) particularmente em Cartas a Alticus (GAMA apud MIRANDA, 2003, p. 29).

\begin{tabular}{|l|l|l|l|l|}
\hline Q Rovista Dialectus & Ano 10 & n. 23 & Maio - Agosto 2021 & p. $156-177$ \\
\hline
\end{tabular}


Também José Bonifácio, em 1815, já utilizava o termo tecnologia. Em textos indiretos sobre o tema, o autor é incisivo sobre a necessidade de que se cessem oposições inúteis. Nas palavras do autor: “[...] quando findará de uma vez entre nós a disputa renhida e fútil entre teóricos e práticos? É certo que nas artes a experiência é a mãe da verdadeira teoria, mas é certo também que uma são teórica e a mestra da genuína prática" (BONIFÁCIO apud GAMA, 1986, p. 40).

Conforme o filósofo e matemático Christian Wolf (1697-1754), citado por Gama (1986), o termo tecnologia abrange um discurso racional sobre a atividade técnica. Desse modo, "a tecnologia é, portanto, a ciência das artes e das obras de arte ou se preferirmos, ciência das coisas que o homem produz com o trabalho dos órgãos de seu corpo, principalmente com as mãos" (GAMA 1986, p. 71). Esse filósofo é considerado o primeiro a tentar definir a palavra no sentido mais estritamente moderno.

Já nos Estados Unidos, o termo “technology” foi usado em 1829 por Jacob Bigelow, em conferências realizadas em Harvard no começo do século XIX. Aqui, busca-se a reunião da ciência com a técnica. Assinale-se que, quando fundado o MIT (Massachussets Institute of Technology), a palavra que qualifica a nova instituição foi adotada por proposta de Bigelow.

Essas breves menções de cunho semântico apontam para a dificuldade de uma definição precisa do termo, no entanto, a temática envolve permanentemente alguns elementos recorrentes. Certamente, nessa heterogênese do conceito se misturam incessantemente múltiplas relações entre conhecimento teórico e conhecimento prático, entre saber e fazer. Todavia, será um conjunto de fatores político-econômicos, históricos, sociais, culturais e filosóficos que propiciarão transformações e assim incidirão na noção mesma de tecnologia.

Voltando-nos novamente para a classificação de Ortega y Gasset (1991), essa nova fase é denominada de "técnica do técnico". São vários elementos de diferenciação e mesmo ruptura com a fase anterior (a técnica do artesão). Para Ortega y Gasset, nessa fase, o instrumento estará em primeiro plano, isto é, o homem complementa a máquina. Essa ruptura torna o elemento técnico praticamente independente do homem. Também se pode notar a separação aguda entre o técnico e o trabalhador. Mas o que mais caracteriza essa fase é que o homem se dará conta de que tem uma capacidade distinta das capacidades rígidas, pouco mutáveis, que integram a sua porção natural ou animal. Percebe, então, que a técnica não é um acaso nem dada apenas aos artesãos. Percebe ainda que a técnica não se reduz a elementos determinados e fixos, mas é um manancial ilimitado de atividades humanas. Essa situação é radicalmente nova. Até então o homem conseguia perceber o que não podia fazer e o que era

\begin{tabular}{|c|c|c|c|c|}
\hline Q $R$ ovista Dialectus & Ano 10 & n. 23 & Maio - Agosto 2021 & p. 156 - 177 \\
\hline
\end{tabular}


incapaz de realizar. Agora, há um novo cenário, no qual prevalecem as potencialidades, em princípio, sem limites. Com isso, a inventividade humana é lançada para horizontes históricos surpreendentes (ORTEGA Y GASSET, 1991).

Desse modo, ainda que em sentido amplo, pode-se afirmar que a noção de tecnologia se constitui na modernidade, quando se percebe que tudo o que se constrói é regido por leis científicas e pode ser compreendido por meio de teorias explicativas. Com a emergência e a consolidação do capitalismo nos séculos XVII e XVIII, seguidas da revolução industrial, as ligações entre as ciências e a necessidade de resolução de problemas técnicos ficou fortalecida. É nesse ínterim que surge uma nova etapa do desenvolvimento técnico, ou seja, a da tecnologia. Aduzindo as observações de Miranda (2003), a ciência moderna, uma vez metodologicamente articulada, precisava expandir sua atuação e exigia instrumentos de pesquisa cada vez mais sofisticados na busca da mensuração precisa. Dois fatos cooperaram para o aparecimento da tecnologia como uma aproximação da técnica com a ciência moderna. De acordo com Vargas (2003, p. 29):

O primeiro foi o aparecimento, na Europa, de uma crença de que tudo que pudesse ser
feito pelo homem poderia sê-lo por intermédio de conhecimentos científicos. O
segundo foi que a ciência experimental exigiria para seus experimentos instrumentos
de medida precisos que teriam que ser fabricados ou por cientistas com dotes
artesanais ou por artesãos informados pelas teorias científicas. Essa, sem dúvida, foi
a origem da tecnologia como utilização das teorias científicas na solução de problemas
técnicos [...]. O primeiros sucessos apareceram ao se explicar o funcionamento das
máquinas a vapor por meio de teorias científicas para a construção de máquinas
elétricas e confirmou-se com a eletrônica; não se sabe exatamente onde termina a
ciência e começa a técnica.

Note-se que a citação tem sua força na ênfase na vinculação, aliança, imbricação entre técnica e ciência. Sugere-se, portanto, que a tecnologia começa no ponto em que ciência e técnica se confundem ou se implicam. Essa mútua implicação é tão forte que se torna difícil estabelecer critérios para distinguir os dois termos. Para Rui Gama e Milton Vargas, uma tentativa de separação entre ciência pura e tecnologia não faz muito sentido, sobretudo após o desenvolvimento científico da Segunda Guerra. É conhecido que a bomba atômica, o radar, as conquistas espaciais ocorreram de tal forma que se tornou difícil separar o que é puramente científico do que é técnico. Evidentemente, é possível buscar clareamentos e distinções, mas na prática é difícil separá-las, pois o desenvolvimento de ambas assenta na sua cooperação mútua. Assim, devem ser tratadas como uma unidade inseparável em todos os sentidos ${ }^{11}$.

11 Aqui se aloja um vasto campo de estudos filosóficos e sociológicos contemporâneos, dentre eles, aqueles que demonstram a preocupação social com a tecnologia, também conhecida como perspectiva sociotécnica da ciência e da tecnologia, na qual se acentuam as atividades fronteiriças, mas também interativas. Autores como

\begin{tabular}{|l|l|l|l|l|}
\hline Ronista Dialectus & Ano 10 & n. 23 & Maio - Agosto 2021 & p. 156 - 177 \\
\hline
\end{tabular}


No âmbito dessas considerações, parece oportuno ouvir, mesmo que en passant, algumas vozes e intensidades dominantes dessa discussão situadas no contexto da modernidade.

\section{Modernidade Fáustica}

Moderno, modernidade, modernismo. Essas palavras são polissêmicas e não remetem a ideias claras e distintas nem a conceitos fechados. A modernidade adota facilmente uma postura provocante, mas seu interior é desesperado (COMPAGNON, 1996). Daí a necessidade de fugir da tentação da miragem de síntese, que não quer admitir as contradições nem o caráter aporético dos problemas aí encontrados. Se o substantivo "modernidade", no sentido de caráter do que é moderno, aparece em Balzac, em 1823; e se "modernismo", no sentido de gosto julgado excessivo pelo que é moderno, aparece em Huysmans, em 1879; o adjetivo "moderno" é muito mais antigo.

Para Abbagnano (2000), a noção de moderno enquanto adjetivo foi introduzida pelo latim pós-clássico e significa literalmente "atual" (de "modo" = agora); além disso, foi empregada pela Escolástica a partir do século XIII para indicar a nova lógica terminista, designada como via moderna em comparação com a via antiga da lógica aristotélica.

De acordo com Hans Robert Jauss apud Compagnon (1999, p. 17):

[...] modernus aparece, em latim vulgar, no fim do século V, oriundo de modo, "agora mesmo, recentemente, agora". Modernus designa não o que é novo, mas o que é presente, atual, contemporâneo daquele que fala. $\mathrm{O}$ moderno se distingue, assim, do velho e do antigo, isto é, do passado totalmente acabado da cultura grega e romana. Os moderni contra os antiqui, eis a oposição inicial, a do presente contra o passado.

Toda a história da palavra e de sua evolução semântica será a da redução do lapso de tempo que separa o presente do passado, ou seja, a da aceleração da história. Pouco importa que essa aceleração seja uma realidade ou uma ilusão e que se passem, realmente ou não, mais coisas em um instante dos tempos modernos do que em um instante da antiguidade, pois é a percepção do tempo que conta. ${ }^{12}$

Latour (2001), ao explorar o conceito de Rede de Atores, avançam no sentido de propor uma espécie de tratamento conjunto da ciência e da tecnologia. A ciência não consistiria em pura teoria, nem a tecnologia em pura aplicação, senão que ambas seriam integrantes de redes de cujos nós também fazem parte todo tipo de instrumentos, seres e objetos relevantes à atividade que se desenvolve no seu entrono. Os produtos da atividade científica - as teorias - não poderiam então continuar sendo separadas dos instrumentos — as tecnologias, inclusive - que participam da sua elaboração.

12 Compagnon (1999, p. 16) esclarece que, quando a palavra modernus surgiu, nem se cogitava o tempo. A separação entre o antigo e o moderno não implica o tempo (no século $\mathrm{V}$ modernus não contém ainda a ideia de tempo); ela é total, absoluta, entre a antiguidade grega e romana e o aqui e agora medieval; aqui e agora é o conflito do ideal e do atual. Já no século XII, por ocasião do que se chama de primeira Renascença, o lapso de tempo que define os moderni face aos antiqui equivale apena a algumas gerações. Perguntou-se muito se, desde

\begin{tabular}{|c|c|c|c|c|}
\hline Rovita Didectus & Ano 10 & n. 23 & Maio - Agosto 2021 & p. $156-177$ \\
\hline
\end{tabular}


Nessa percepção dos acontecimentos modernos e da postura adotada com relação à ciência e à técnica, vamos trazer agora alguns personagens interessantes. O primeiro funciona como uma testemunha inquieta de seu tempo. Trata-se de Jean Jacques Rousseau (1712-1778).

Rousseau é uma voz moderna arquetípica. Será o primeiro a usar a palavra moderniste no sentido em que os séculos XIX e XX a usarão; ele é a matriz de algumas das mais vitais tradições modernas (BERMAN, 2007). Rousseau tinha uma sensibilidade aguçada em face às condições sociais que começavam a moldar a vida de milhões de pessoas. O filósofo inquietará seus contemporâneos indicando que a sociedade de seu tempo estava "à beira do abismo", no limite das mais explosivas conturbações revolucionárias (Rousseau viveu antes da revolução francesa). Ele experimentou a vida cotidiana nessa sociedade, particularmente em Paris, em meio ao tourbillon social, ou seja, em meio a um redemoinho social. Além disso, como testemunha de seu tempo, fez várias perguntas inquietantes, como as que fazemos contemporaneamente a respeito das relações entre ciência, tecnologia e sociedade.

Em um de seus escritos, O Discurso sobre as Ciências e as Artes, Rousseau procura responder a uma pergunta que lhe havia sido feita pela Academia de Dijon: "o restabelecimento (leia-se 'o progresso') das ciências e das artes contribuiu para aprimorar ou para corromper os costumes? Eis o que é preciso examinar" (ROUSSEAU, 1978, p. 341). Para elaborar a resposta - que lhe rendeu o primeiro prêmio da Académie — o filósofo fez outras perguntas, nada elementares, como as que seguem: existe alguma razão para substituirmos o conhecimento vulgar (de senso comum) que temos da natureza e da vida pelo conhecimento científico? Será que a ciência poderá contribuir para diminuir as diferentes distâncias crescentes na sociedade? Distâncias sociais, distâncias entre o que se é o que se aparenta ser, entre dizer e fazer ou (como dizemos frequentemente) entre a teoria e a prática? Na sua época, Rousseau respondeu aos questionamentos, taxativa e estrondosamente, com um vigoroso "não!".

Quando Rousseau escreveu o texto acima referido, no século XVIII, já havia o fermento de uma transformação técnica e social sem precedentes na história da humanidade ${ }^{13}$.

o século XII, a noção já incluía a ideia de um progresso que evoluiria dos antiqui aos moderni, ideia inseparável de nossas concepções da época moderna.

13 Para efeito ilustrativo, é bom ter presente a paisagem altamente desenvolvida e diferenciada e que será reinante um século mais tarde, já no XIX, e que nos dá indícios da vivência moderna. Trata-se de uma paisagem de engenhos a vapor, fábricas automatizadas, ferrovias, amplas novas zonas industriais, cidades que cresceram do dia para a noite, jornais, telégrafos, Estados Nacionais cada vez mais fortes, movimentos sociais de massa que lutam contra as modernizações de cima para baixo, um mercado mundial em expansão capaz de devastação e desperdício incalculáveis (BERMAN, 2007).

\begin{tabular}{|c|c|c|c|c|}
\hline Q Rovista Dialectus & Ano 10 & n. 23 & Maio - Agosto 2021 & p. $156-177$ \\
\hline
\end{tabular}


Uma fase de transição que deixava inquietos, conforme Santos (2003, p. 17), "os espíritos mais atentos e os fazia refletir sobre os fundamentos da sociedade em que viviam e sobre o impacto das vibrações a que eles iam ser sujeitos por via da ordem científica emergente". A voz de Rousseau é, portanto, de ceticismo diante das mudanças que presenciava.

Outras vozes podem ser ouvidas em meio a essa paisagem. O Fausto, de Goethe (1749-1832), expressa e dramatiza o processo pelo qual, no fim do século XVIII e início do seguinte, um sistema mundial especificamente moderno vem à luz. A força vital que o conduz é o impulso e o desejo de desenvolvimento. Berman (2007) esclarece que Fausto explica esse desejo ao diabo (Mefistófeles), porém não é fácil fazê-lo. Em outras passagens, Fausto vendia sua alma em troca de determinados bens, claramente definidos e desejados: dinheiro, sexo, poder, fama, glória. O Fausto de Goethe diz a Mefistófeles que, sim, ele deseja todas essas coisas, mas não pelo que elas representam em si mesmas. Uma passagem ilustra essa percepção.

\author{
MEFISTÓFELES \\ Não ponho restrições; peça por boca! \\ Se as primícias quiserem, libar de tudo, \\ de qualquer coisa (por fugaz que seja) \\ se quiser na voadura apoderar-se, \\ não faça cerimônia; e que lhe preste! \\ FAUSTO \\ Entendamo-nos bem. Não ponho eu mira \\ na posse do que o mundo alcunha gozos. \\ O que preciso e quero, é atordoar-me. \\ Quero a embriaguez de incomportáveis dores \\ a volúpia do ódio, o arroubamento \\ das sumas aflições. Estou curado \\ das sedes do saber; de ora em diante \\ às dores todas escancaro est' alma. \\ As sensações da espécie humana em peso, \\ quero-as eu dentro em mim; seus bens, seus males \\ mais atrozes, mais íntimos, se entranhem \\ aqui onde à vontade a mente minha \\ os abrace, os tateie; assim me torno \\ eu próprio a humanidade; e se ela ao cabo \\ perdida for, me perderei com ela. \\ MEFISTÓFELES \\ Pode crer (há muitos mil janeiros \\ que eu ando a roer nisto), inda não houve \\ homem nenhum que desde o berço à cova \\ lograsse digerir esse fermento. \\ O complexo do mundo (e pode crê-lo,
}


pois lho afirma um diabo) é incompreensível a todos salvo a Deus $[\ldots] .{ }^{14}$

O que esse Fausto deseja para si próprio era um processo dinâmico que incluísse toda sorte de experiências humanas, nos seus opostos, alegria e desgraça juntas, assimilando-as dentro de si próprio. Perceba-se que até mesmo uma espécie de destruição está contemplada. A réplica de Mefistófeles é irônica, como a própria modernidade.

O Fausto de Goethe destaca uma grande afinidade entre o ideal cultural do autodesenvolvimento e o efetivo movimento social na direção do desenvolvimento econômico. Goethe acredita que essas formas de desenvolvimento devem caminhar juntas, fundir-se em uma só. Para isso, o homem moderno dispõe, para se transformar, da radical mudança de todo o mundo físico, social, político em que vive. O heroísmo do Fausto de Goethe provém da liberação de forças e tremendas energias humanas reprimidas, não só nele próprio, mas em todos os que ele toca e, eventualmente, em toda a sociedade ao seu redor. Não obstante, o grande desenvolvimento que Fausto inicia tem um custo extremamente alto para o homem. Esse é um sentido para o diálogo faustiano com o diabo. Para Berman (2010, p. 54): "o Fausto de Goethe é a primeira e ainda a melhor tragédia do desenvolvimento". É uma tragédia com ingredientes da razão moderna e protagonizado pelas ações, conflitos, sentimentos, possibilidades, ambiguidade e grandes contradições humanas.

Como Prometeu, a tecnociência se dispôs a controlar a natureza para proporcionar à espécie humana o que entendia ser uma vida melhor. A ciência parecia ser o instrumento necessário para construir uma sociedade iluminada, racional. Assim, o conhecimento moderno inscreve-se numa tradição prometeica fundada numa crença de ascendência, linearidade, avanços permanentes, isto é, progresso. Os sucessivos êxitos fizeram surgir o desejo permanente de controle da natureza. Na medida em que esse processo se desenvolve, a ciência prometeica torna-se ciência fáustica, e seu desenrolar histórico será avaliado atentamente por meio de incontáveis reações e críticas.

Com efeito, os breves murmúrios registrados até aqui colaboram para introduzir esse tenso e denso debate que permanece aberto a outras incursões de viés simbólico, cultural, axiológico, epistemológico, enfim, filosófico. Daqui resulta a compreensão de que qualquer atribuição de um sentido único à técnica só pode ser dúbia, pois, junto à técnica, se desdobra a

14 Optamos por incluir uma citação mais ampla e direta da obra, em português, do que aquela citada por Berman (2007), retirada do Quadro V, Cena I da peça FAUSTO, escrita por Goethe, em tradução de Antonio Feliciano de Castilho e versão digital da BookLibris@eBooksBrasil.com 2003.

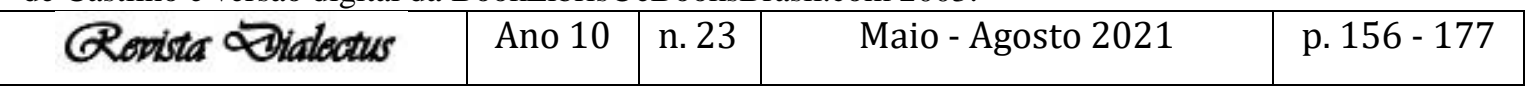


experimentação humana, que envolve ideias, projetos de transformação da natureza, projetos sociais, utopias, interesses econômicos, estratégias de poder. Portanto, a pesquisa que envolve a tríade técnica-ciência-tecnologia implica estabelecer conexões que transversalizem distintos discursos e campos do conhecimento.

\section{Referências}

ALENCASTRO, M. S. Aspectos do pensamento ético frente à modernidade tecnológica. Dissertação de mestrado. Curitiba, Centro Federal de Educação Tecnológica do Paraná, Programa de Pós-graduação em Tecnologia, 2003.

BERMAN, M. Tudo o que é sólido desmorona no ar. São Paulo: Companhia das Letras, 2007.

BERNAL, J. D. Science in history. Trad. Antonio Neves Pedro. Lisboa: Livros Horizonte, 1969. v. 2.

COMPAGNON, A. Os cinco paradoxos da modernidade. Belo Horizonte: UFMG, 1999.

CUPANI, A. Filosofia da tecnologia: um convite. Florianópolis: UFSC, 2011.

CHAUÍ, M. Convite à filosofia. 13. ed. São Paulo: Ática, 2004.

ÉSQUILO. Prometeu acorrentado. Trad. J. B. de Mello e Souza. [e-book] eBooksBrasil.com, 2005. Disponível em: http://www.ebooksbrasil.org/eLibris/prometeu.html.

GAMA, R. A tecnologia e o trabalho na história. São Paulo: Livraria Nobel S. A., 1986.

GOETHE, J. W. von. Fausto. Trad. Antonio Feliciano de Castilho. [e-book] Disponível em: http://www.ebooksbrasil.org/eLibris/faustogoethe.html. Acesso em: 12 jan. 2012.

HESÍODO. Os trabalhos e os dias. Trad. Mary de Camargo Neves Lafer. 3 ed. São Paulo: Iluminuras, 1996.

LATOUR, B. A esperança de Pandora: ensaios sobre a realidade dos estudos científicos. Trad. Gilson César Cardoso de Sousa. Bauru: EDUSC, 2001.

MIRANDA, A. L. Da natureza da tecnologia: uma análise filosófica sobre as dimensões ontológicas, epistemológica e axiológica da tecnologia moderna. Dissertação de mestrado. Curitiba, Centro Federal de Educação Tecnológica do Paraná, Programa de Pós-graduação em Tecnologia, 2002.

MITCHAM, C. Que és la filosofia de la tecnologia? Barcelona: Antropos, 1989.

MOTOYAMA, S. (org.). Educação técnica e tecnológica em questão. São Paulo: UNESP, 1996.

\begin{tabular}{|c|c|c|c|c|}
\hline Q Rovita Dialectus & Ano 10 & n. 23 & Maio - Agosto 2021 & p. $156-177$ \\
\hline
\end{tabular}


PLATÃO. Protágoras - Górgias - Fédon. Trad. Carlos Alberto Nunes. 2. ed. Belém: EDUFPA, 2012.

REALE, G.; ANTISERI, D. História da filosofia. 4. ed. São Paulo: Paulus, 1990. v. 2.

REALE, G. História da filosofia Antiga. São Paulo: Paulus, 1995. v.1

VARGAS, M. Para uma filosofia da tecnologia. São Paulo: Alfa-Ômega, 1994.

VARGAS, M. Metodologia da pesquisa tecnológica. São Paulo: Alfa-Ômega, 2003. 